\title{
Removal of Disinfection By-products Formation Potential by Combination of Preoxidation and Coagulation Sedimentation Processes
}

\author{
Song Chen ${ }^{1,}$, Wenyi Dong ${ }^{1, b}$ \\ ${ }^{1}$ Harbin Institute of Technology Shenzhen Graduate School, Shenzhen Key Laboratory of Water \\ Resource Utilization and Environment Pollution Control, Shenzhen, 518055, China
}

achensong9312@qq.com, b

\begin{abstract}
Keywords: High natural matter; Pre-oxidation; Coagulation sedimentation; Disinfection by-products formation potential

Abstract. Pre-oxidation is widely used to remove synergistically algae, odor and natural organic matter $(\mathrm{NOM})$ for drinking water treatment. Permanganate $\left(\mathrm{KMnO}_{4}\right)$, ozone $\left(\mathrm{O}_{3}\right)$, and hydrogen peroxide $\left(\mathrm{H}_{2} \mathrm{O}_{2}\right)$ in combination with polyaluminum chloride (PAC) coagulation for assisting the removal of NOM and disinfection byproduct formation potential (DBPFP). DBPFP investigated included trihalomethanes formation potential (THMFP), haloacetic acids formation potential (HAAFP) and chloral hydrate formation potential (CHFP). The results showed that pre-oxidation with $\mathrm{KMnO}_{4}$ and pre-ozonation can increase the removal rate of THMFP and HAAFP. Pre-oxidation with $\mathrm{KMnO}_{4}$ can also increase the removal rate of CHFP, however, pre-ozonation can decrease the removal rate of CHFP. Pre-oxidation with $\mathrm{H}_{2} \mathrm{O}_{2}$ had no significant effect on the removal rate of DBPFP. $\mathrm{KMnO}_{4}$ is the best choice for assisting the removal of NOM and DBPFP, and optimal dosage was in range from 0 to $1 \mathrm{mg} / \mathrm{L}$.
\end{abstract}

\section{Introduction}

Since the discovery of disinfection by-products (DBPs) in the early 1970s [1], more than 600 DBPs have been reported [2]. Among these DBPs, trihalomethanes (THMs) and haloacetic acids (HAAs) are the two major classes in chlorinated drinking water [3]. Besides THMs and HAAs, chloral hydrate $(\mathrm{CH})$ is the next most prevalent DBP in drinking water [4]. Natural organic matter (NOM) is a critically important source of DBP precursor [5]. Therefore, a key approach for controlling DBPs in finished drinking water is to maximize the removal of NOM prior to chlorination [6]. Conventional treatment, including coagulation, clarification, and particle filtration, is commonly used to remove NOM. However, conventional treatment is not the effective method for high NOM content water. Pre-oxidation can enhance removal of natural organic matter [7]. For this reason, the effectiveness of pre-oxidants for NOM and DBP precursor removal has been an active area of research.

Potassium permanganate $\left(\mathrm{KMnO}_{4}\right)$, ozone $\left(\mathrm{O}_{3}\right)$, and hydrogen peroxide $\left(\mathrm{H}_{2} \mathrm{O}_{2}\right)$ are often considered as alternative pre-oxidants to chlorine $\left(\mathrm{Cl}_{2}\right)$ and chlorine dioxide $\left(\mathrm{ClO}_{2}\right)$, which have been shown to form regulated halogenated disinfection byproducts (DBPs) and chlorite $\left(\mathrm{ClO}_{2}\right) . \mathrm{KMnO}_{4}$ pre-oxidation [8] can enhance algal cell removal and control chlorinated DBPs. The impacts of $\mathrm{O}_{3}$ on coagulation for NOM and DBP precursor removal are conflicting and site specific $[9,10] . \mathrm{O}_{3}$ or $\mathrm{O}_{3} / \mathrm{H}_{2} \mathrm{O}_{2}$ pretreatments may provide some benefits for the chloramination process in controlling regulated and emerging DBPs in waters without high bromide content [11]. The objective of this study was to examine the effect of pre-oxidation $\left(\mathrm{KMnO}_{4}, \mathrm{O}_{3}\right.$ or $\left.\mathrm{H}_{2} \mathrm{O}_{2}\right)$ as a strategy to enhance the removal rate of DBPFP.

\section{Materials and methods}

Source water characterization. High NOM water used in this study was from a certain Lake in Shenzhen.

Chemicals and reagents. Chemical solutions were prepared from reagent-grade chemicals and water purified using the Milli-Q biocel system $(18.2 \mathrm{M} \Omega \cdot \mathrm{cm}) . \mathrm{KMnO}_{4}$ were purchased from Xiya Reagent China. $\mathrm{H}_{2} \mathrm{O}_{2}$, sodium hypochlorite solution, four THMs, $\mathrm{CH}$ and two HAAs were purchased 
from Aladdin. A concentrated $\mathrm{O}_{3}$ stock solution (about $20 \mathrm{mg} / \mathrm{L}$ ) was produced by continuously bubbling $\mathrm{O}_{3}$ containing oxygen gas into a flask of Milli-Q water.

Treatment processes. Standard jar tests were conducted in a mixer equipped with six-paddle jar test apparatus. Using different dosages of pre-oxidants to react with the raw water by standard jar tests. After adding different pre-oxidants, samples were stirred at $300 \mathrm{rpm}$ for $5 \mathrm{~min}$, and PAC (8 $\mathrm{mg} / \mathrm{L}$ as $\mathrm{Al}$ ) was added to samples respectively. The samples were stirred at $200 \mathrm{rpm}$ for $5 \mathrm{~min}$ and then at $50 \mathrm{rpm}$ for $5 \mathrm{~min}$, following the samples were allowed to settle quiescently for $30 \mathrm{~min}$. Thereafter, subsequent experiment samples was siphoned $1 \mathrm{~cm}$ below the water surface.

Chlorination and DBP analyses. After combination pre-oxidation and coagulation sedimentation, the samples were subjected to chlorination DBP formation potential tests. Chlorination experiments were conducted in $100 \mathrm{~mL}$ brown glass volumetric flasks with polytetrafluoroethylene lids [12]. And the bottle was partly filled with the water sample, the buffer at $\mathrm{pH}$ of 7.2 and the chlorine solution (chlorine: NPOC ratio was 3:1 on a weight basis) [13]. After the addition of free chlorine, the samples were chlorinated for $24 \mathrm{~h}$ in a dark incubator at $25^{\circ} \mathrm{C}$. Thereafter, ascorbic acid was applied as the de-chlorination reagent at a dose about 3 times that of the chlorine dosage $[14,15]$.

Analyses of four THMs (TCM, BDCM, DBCM\& TBM), CH and two HAAs (DCAA, TCAA) were carried out with a gas chromatograph (Agilent 6890B) with an electron capture detector (ECD), based on USEPA Method 551.1 and USEPA Method 552.3[16]. The column used was an HP-5 fused silica capillary column $(30 \mathrm{~m} \times 0.25 \mathrm{~mm}$ I.D. with $0.25 \mathrm{~mm}$ film thickness $)$.

\section{Results and discussion}

Raw water characteristics. The raw water was from a certain Lake in Shenzhen. The general raw water characteristics in terms of parameters are presented in Table 1.

Table 1 Raw water characteristics

\begin{tabular}{ccccc}
\hline Parameter & Turbidity(NTU) & DOC $(\mathrm{mg} / \mathrm{L})$ & $\mathrm{UV}_{254}\left(\mathrm{~cm}^{-1}\right)$ & SUVA(L/(mg $\cdot \mathrm{m}))$ \\
\hline Measured range & $8.5 \sim 14.1$ & $7.7 \sim 8.9$ & $0.087 \sim 0.093$ & $0.9 \sim 1.1$ \\
\hline
\end{tabular}

Optimal parameter of coagulation sedimentation. Fig. 1 shows the influence of PAC dosage on conventional index (turbidity and $\mathrm{UV}_{254}$ ). When PAC dosage was in range from 0 to $8 \mathrm{mg} / \mathrm{L}$, the removal rate of turbidity were increased. The removal rate of $\mathrm{UV}_{254}$ was first increased and then decreased with PAC dosage increasing. The optimal dosage was $8 \mathrm{mg} / \mathrm{L}$.
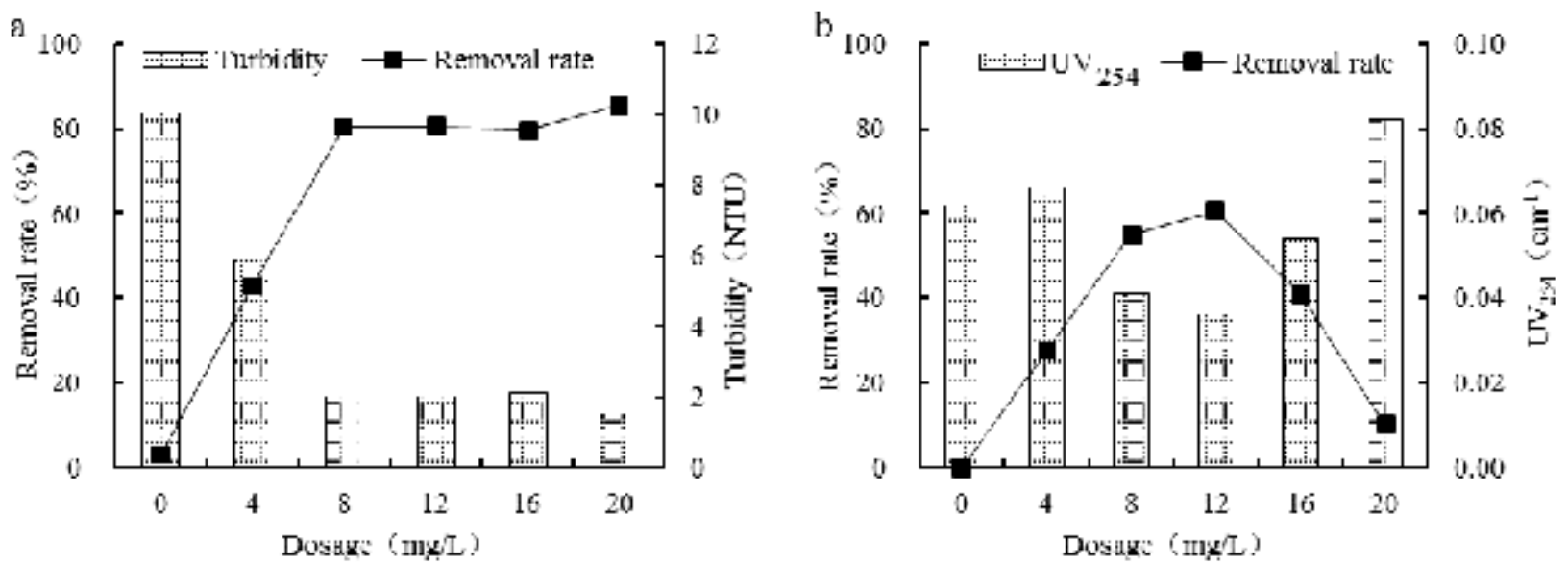

Fig. 1 Influence of PAC dosage on conventional index.(a) Turbidity, (b) $\mathrm{UV}_{254}$

The influence of potassium permanganate pre-oxidation on DBPFP. To explore different dosages in combination of pre-oxidation and coagulation sedimentation impact on DBPFP (THMFP, HAAFP, and CHFP). The experimental results are shown in Fig. 2 

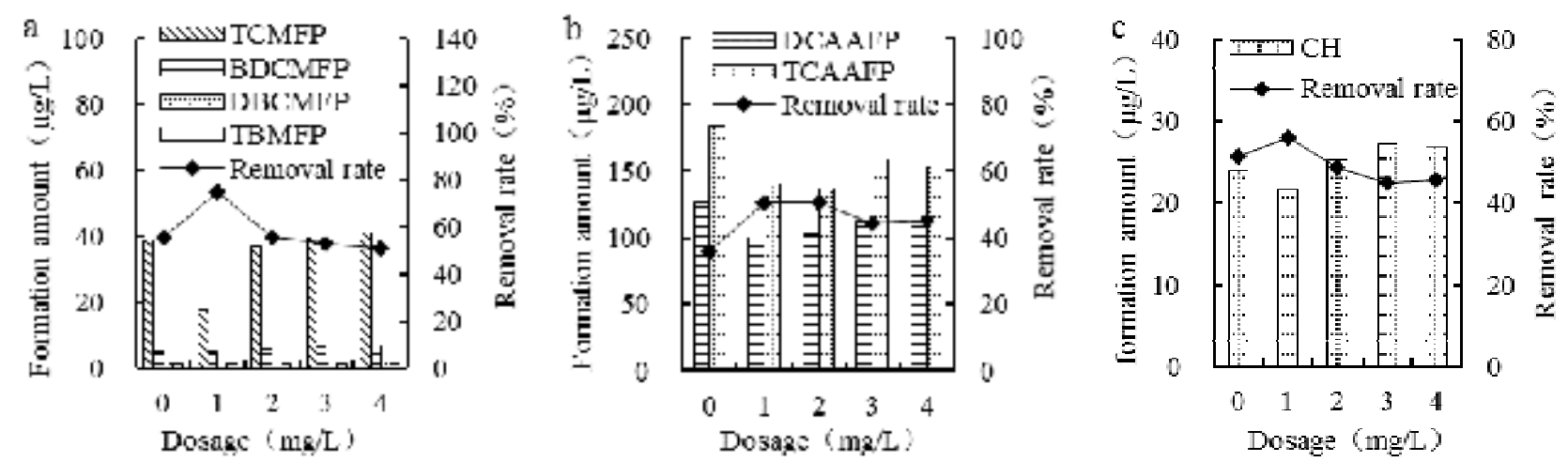

Fig. 2 Influence of dosage potassium permangante on DBPFP.(a) THMFP, (b) HAAFP,(b) CHFP

As can be seen from Fig. 2, the removal rate of DBPFP was first increased and then decreased with dosage increasing. Low dosage of permanganate can enhance coagulation that removing more NOM. Related research showed that in combination of permanganate pre-oxidation and coagulation can increase the removal rate of $\mathrm{NOM}$ (molecular weight $<1 \mathrm{kDa}$ ), which was advantaged to alone coagulation process [17]. The optimal dosage was range from 0 to $1 \mathrm{mg} / \mathrm{L}$.

The influence of ozone pre-oxidation on DBPFP. To explore different dosage in combination of pre-oxidation and coagulation sedimentation impact on DBPFP (THMFP, HAAFP, and CHFP). The experimental results are shown in Fig. 3.
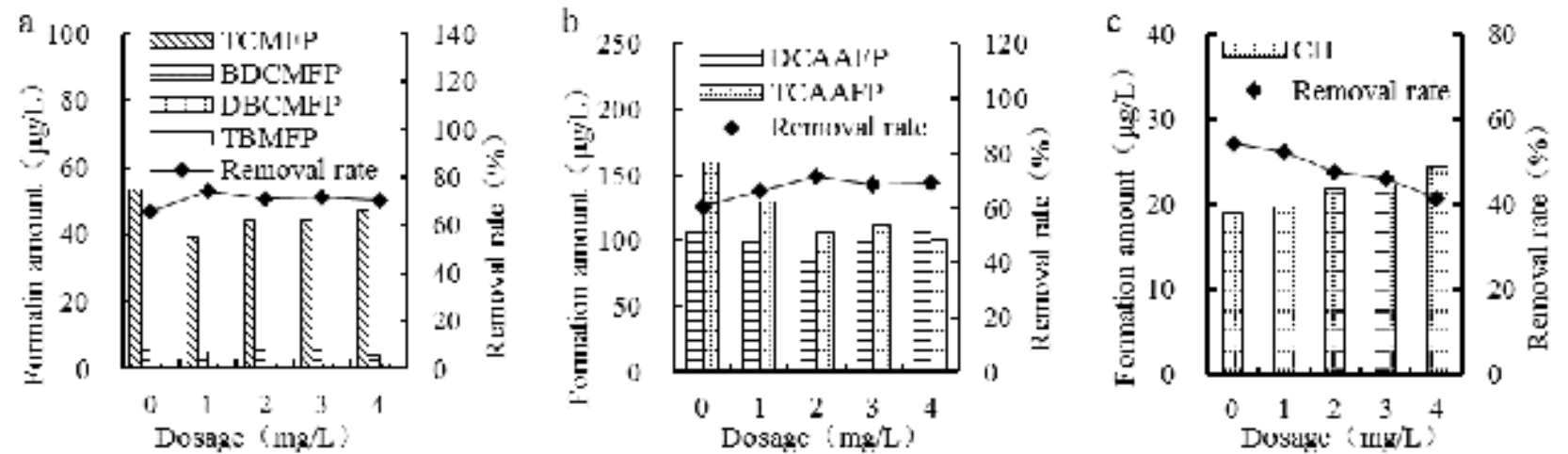

Fig. 3 Influence of dosage ozone on DBPFP.(a) THMFP, (b) HAAFP,(b) CHFP

As can be seen from Fig. 3, removal rate of THMFP and HAAFP were increased and then decreased with dosage increasing while CHFP was decreased. Because ozone might transform the hydrophobic NOM to hydrophilic NOM [18]. Considering the impact of conventional index, the optimal dosage was range from 0 to $1 \mathrm{mg} / \mathrm{L}$.

The influence of hydrogen peroxide pre-oxidation on DBPFP. To explore different dosage in combination of pre-oxidation and coagulation sedimentation impact on DBPFP (THMFP, HAAFP, and CHFP). The experimental results are shown in Fig. 4.
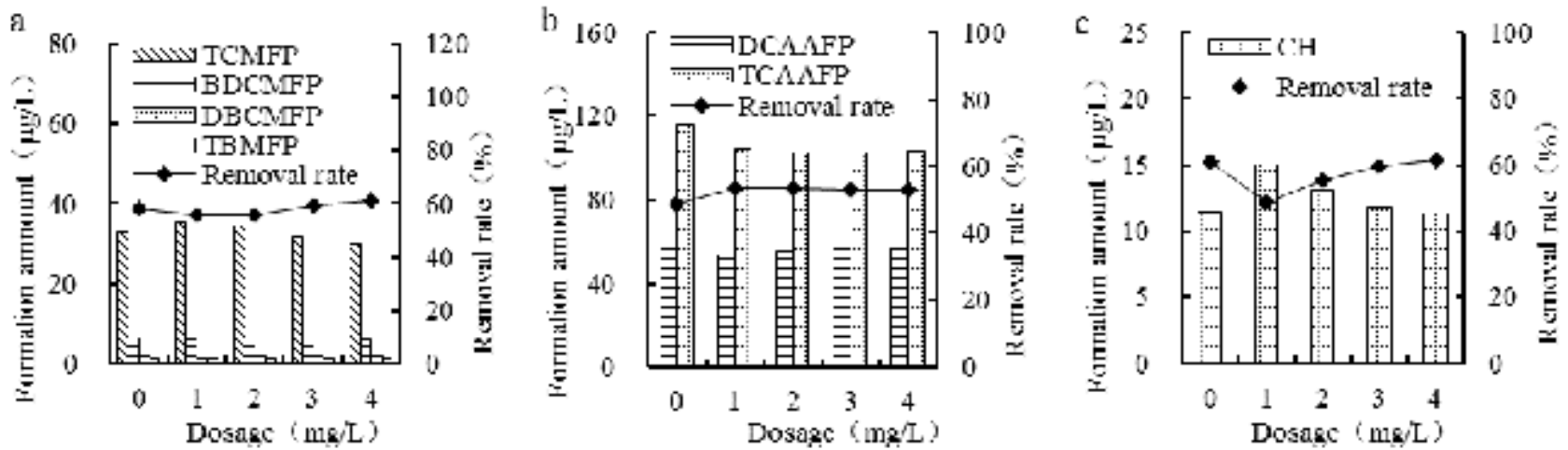

Fig. 4 Influence of dosage peroxide preoxidation on DBPFP.(a) THMFP, (b) HAAFP,(b) CHFP

As can be seen from Fig.4, removal rate of THMFP, HAAFP and CHFP had no significant effect with dosage increasing. So hydrogen peroxide was not considering as pre-oxidation method. 


\section{Conclusions}

Pre-oxidation with $\mathrm{KMnO}_{4}$ and $\mathrm{O}_{3}$ generally achieved comparable lower in THMFP and HAAFP, whereas $\mathrm{O}_{3}$ led to higher CHFP than $\mathrm{KMnO}_{4}$. However, Pre-oxidation with $\mathrm{H}_{2} \mathrm{O}_{2}$ had no effect on enhancing the removal of DBPFP. The optimal pre-oxidation is $\mathrm{KMnO}_{4}$, which was effective on controlling THMFP, HAAFP and CHFP. $\mathrm{KMnO}_{4}$ is the best choice for assisting the removal of NOM and DBPFP, and optimal dosage was in range from 0 to $1 \mathrm{mg} / \mathrm{L}$.

\section{Acknowledgements}

This work was financially supported by the National Major Science and Technology Program for Water Pollution Control and Treatment (2015ZX07406-004).

\section{References}

[1] T.A. Bellar, J.J. Lichtenberg, R.C. Kroner, Journal, Vol. 66 (1974), p. 703.

[2] S.D. Richardson, M.J. Plewa, E.D. Wagner, R. Schoeny, D.M. Demarini, Mutation Research Reviews in Mutation Research, Vol. 636 (2007), p. 178.

[3] S.D. Richardson, Trends in Analytical Chemistry, Vol. 22 (2003), p. 666.

[4] A. Dabrowska, J. Nawrocki, WATER RES, Vol. 43 (2009), p. 2201.

[5] S.W. Krasner, P. Westerhoff, B. Chen, B.E. Rittmann, S.N. Nam, G. Amy, ENVIRON SCI TECHNOL, Vol. 43 (2009), p. 2911.

[6] J.G. Pressman, S.D. Richardson, T.F. Speth, R.J. Miltner, M.G. Narotsky, E.S.I. Hunter, G.E. Rice, L.K. Teuschler, A. Mcdonald, S. Parvez, ENVIRON SCI TECHNOL, Vol. 44 (2010), p. 7184.

[7] M.S. Siddiqui, G.L. Amy, B.D. Murphy, WATER RES, Vol. 31 (1997), p. 3098.

[8] P. Xie, J. Ma, J. Fang, Y. Guan, S. Yue, X. Li, L. Chen, ENVIRON SCI TECHNOL, Vol. 47 (2013), p. 14051.

[9] E.C. Wert, F.L. Rosario-Ortiz, Ozone Science \& Engineering, Vol. 33 (2011), p. 14.

[10]P. Bose, D.A. Reckhow, WATER RES, Vol. 41 (2007), p. 1516.

[11]X. Yang, J. Peng, B. Chen, W. Guo, Y. Liang, W. Liu, L. Liu, J HAZARD MATER, Vol. 239-240 (2012), p. 348.

[12]H. Huang, Q.Y. Wu, X. Tang, R. Jiang, H.Y. Hu, CHEMOSPHERE, Vol. 144 (2016), p. 297.

[13]W. Qianyuan, L. Chao, D. Ye, W. Wenlong, H. Huang, WATER RES, Vol. 95 (2016), p. 260.

[14]Q. Wang, P. Shi, Y. Ma, A. Li, J. Wang, R. Ma, X. Chen, CHEM ENG J, Vol. 254 (2014), p. 230.

[15]B. Zhang, Q. Xian, J. Zhu, A. Li, T. Gong, CHEM ENG J, Vol. 279 (2015), p. 258.

[16] W.G. Walter, Standard methods for the examination of water and wastewater, APHA, 1971.

[17] M.T. Valade, W.C. Becker, J.K. Edzwald, Aqua, Vol. 58 (2009), p. 424.

[18]M.T.O. de Velásquez, A.E. Campos-Reales-Pineda, I. Monje-Ramirez, I.Y. Noguez, Ozone Science \& Engineering, Vol. 32 (2010), p. 323. 